\title{
Gender differences in characteristics of drug users presenting to a Dublin syringe exchange
}

Tony Geoghegan, Mary O’Shea \& Gemma Cox

Ir J Psych Med 1999; 16 (4): 131-135

Tony Geoghegan, Director of Merchant's Quay, MA, Dip

Addiction, Mary O'Shea, Assistant Director of Clinical Services, CQSW, Dip Addiction, *Gemma Cox, Research officer, PhD,

The Merchant's Quay Project, Drug/HIV Service, 4 Merchant's

Quay, Dublin 8, Ireland.

*Correspondence

SUBMITTED: SEPTEMBER 30, 1998, ACCEPTED: OCTOBER 4, 1999.

\begin{abstract}
Objectives: This study explores the gender difference in patterns of drug use, risk behaviour, health and well-being among 934 new attenders at a Dublin syringe exchange.

Method: Over the period May 1997 to April 1998 data was collected by means of structured interviews with all clients who presented for the first time at Merchant's Quay health promotion unit. All information collected was based on clients' self-reported behaviour.

Results: Of the new clients, $24.3 \%$ were female and $75.7 \%$ were male. The female clients were significantly younger than their male counterparts $(p<0.0001)$. The women were significantly more likely to report having a sexual partner who was an injecting drug user (OR 9.04, 95\% CI, 5.913.9) and to be living with an injecting drug user (OR 1.69, 95\% CI, 1.2-2.3). They were also significantly more likely to share injecting equipment with their sexual partner $(\mathrm{OR}=3.83,95 \% \mathrm{CI}$, 2.7-5.5) and to report recently sharing injecting paraphernalia $(\mathrm{OR}=1.79,95 \% \mathrm{CI}, 1.3-2.5)$. However, the interval between initiating intravenous drug use and first presenting at the Merchant's Quay health promotion unit was significantly shorter for female clients $(\mathrm{p}<0.0001)$.

Conclusions: One of the most important concerns with regard to illicit intravenous drug use is that of needle sharing, and the associated risks of infection with human immunodeficiency virus and hepatitis. This study highlights the greater personal involvement of women with other drug users, and its consequences in terms of health-related problems and risk behaviour. There is a need to address this issue, by taking advantage of the fact that women present for treatment at a younger age than their male counterparts and at a much earlier stage in their injecting career.
\end{abstract}

Key words: Gender; Drug use; Risk behaviour; Consequences of illicit drug use.

\section{Introduction}

Concern in Ireland and elsewhere with the spread of human immunodeficiency virus (HIV) led to a recognition that drug services need to be pro-active and not just react to the problems which drug use presents. The working philosophy which locates such interventions within a broad perspective on drug misuse and health has been termed 'harm reduction'. Harm reduction emphasises

This article is a reproduction of that published in: Irish Journal of Psychological Medicine, 1999, 16(4), pp127-131. Pagination may not match that of original. 
practical rather than idealised goals, by attempting to reduce the adverse consequences of drug use among those who continue to use drugs. ${ }^{1}$

The Merchant's Quay Project rose to this challenge by offering a range of non-judgemental services accessible to drug users. In 1992 it expanded its service when it created a health promotion unit including needle exchanges. This unit, as the name suggests, is not intended as a single intervention (the exchange of injecting equipment). Rather it provides a range of services, all of which are considered essential aspects of promoting healthy behaviour among injecting drug users. The harm reduction philosophy has operated successfully in the Merchant's Quay Project. Its ultimate objective is not only to reduce the consequences associated with engaging in risk behaviour, but to guide the individual gradually out of engagement in that problem behaviour. ${ }^{2}$ This paper examines the gender differences in drug use, risk behaviour, health and well-being of clients who present for the first time at Merchant's Quay health promotion unit. Women are the focus of the study for a number of reasons.

Firstly, a significant minority of the new clients presenting at the health promotion unit were female. Secondly, there were notable gender differences in drug use patterns among the new attenders. Thirdly, to date there is no published Irish research which concentrates on gender differences in drug usage. Research undertaken in Ireland concerned with female injecting drug users has primarily concentrated on pregnant opiate users. ${ }^{1,4}$

Although the Merchant's Quay Project conducted comprehensive research into the drug taking practices of male and female drug users over the period of one year, this paper only presents baseline data. Additionally, the focus for analysis is concerned with a number of core issues pertinent to female drugs users: younger and earlier presentation for treatment, more health-related problems, greater personal involvement with other drug users, and the resulting consequences in terms of risk behaviour. This paper makes no attempt to describe either all women who could be classified as drug users, or sub-groups of drug users within this population. Moreover, it does not suggest that female drug users are a homogenous group.

\section{Table 1: Drug using characteristics by gender (continuous variables)}

\begin{tabular}{llllll} 
Gender & \multicolumn{2}{l}{ Male $(\mathbf{n}=\mathbf{7 0 7})$} & \multicolumn{2}{l}{ Female $(\mathbf{n = 2 2 7})$} & \\
Variable & $25 \%$ & $75 \%$ & $25 \%$ & $75 \%$ & $p$ value \\
Age at first contact & 19 & 27 & 19 & 24 & $<0.001$ \\
Age first drug use & 15 & 22 & 16 & 21 & $<0.736$ \\
Age first injected & 18 & 24 & 17 & 22 & $<0.109$ \\
Weeks smoking pre injecting & 24 & 156 & 14 & 130 & $<0.057$ \\
Weeks injecting pre attendance & 16 & 156 & 9 & 104 & $<0.001$ \\
\hline
\end{tabular}

All the participants in this study were drug users who presented for the first time at the Merchant's Quay health promotion unit between May 1, 1997 and April 30, 1998. Data were collected by means of a highly structured interview with all clients at the point of first contact.

In addition to basic information regarding demographic characteristics of clients, the interview schedule covered six major domains; drug treatment, current drug use, injecting risk behaviour, sexual risk behaviour, contact with medical services and health and well-being. All interviews were conducted in private by trained staff at the unit.

Confidentiality was assured, informed consent was obtained and all clients were guaranteed that refusal to partake in the interview would not jeopardise the service they would receive in the health promotion unit. All clients agreed at least in part to comply. The data obtained was based on the self-reported risk behaviour of respondents. It is possible that drug users may provide inaccurate information about their past and current behaviour. ${ }^{5}$

On the one hand, the respondents may be unable to recall past behaviour. Patterns of drug use and sexual practices are complex and undergo changes over time. Consequently it may be very difficult for respondents to recall their behaviour accurately. ${ }^{6}$ Conversely, the respondents may be able to remember their behaviour but be unwilling to reveal sexual and drug using practices that may be 
stigmatised and even illegal. ${ }^{7}$ Be it deliberate or unintentional, invalid self-reported information about sensitive behaviour such as drug using practices and sexual behaviour can bias results.

Notwithstanding these concerns, a variety of approaches have shown that intravenous drug users often provide reasonably accurate self-reports of drug use ${ }^{8}$ and sexual behaviour. ${ }^{9}$ However, the research suggests that the recall period should be kept as short as possible. Consequently, during the interview respondents were asked to recall information primarily from two retrospective periods, behaviour over the previous four weeks, and over the previous three months. This design was used to minimize the possibility of recall bias.

Moreover, at first visit, clients' upper extremities were examined for evidence of needle marks to determine skin condition at injecting sites. Although not presented, this information is recorded as a means of validating clients' self-reported drug use. ${ }^{10}$ The data presented in this paper represents the total population of new clients attending the health promotion unit $(n=934)$ between May 1, 1997 and April 30, 1998. In order to examine the gender differences in self-reported behaviour for continuous variables, Mann Whitney tests were employed to compare groups. Categorical variables were analysed using chi-square with odds ratios and corresponding 95\% confidence intervals. Percentages are based on the above returns or valid responses, adjusted for missing data. Missing data includes information not collected by staff at the health promotion unit, and nonresponses by clients.

\section{Results}

Drug use

Of the 934 respondents, $24.3 \%(\mathrm{n}=227)$ were women and $75.7 \%(\mathrm{n}=707)$ were men. Table 1 reveals that the first visit female clients were significantly younger than their male counterparts $(\mathrm{p}<$ 0.001 ). Women were on average 22 years (range 15-37 years) at the point of first contact with the health promotion unit, while men were on average 24.2 years old (range 14-52 years).

There was no significant gender difference in the age of first drug use (excluding alcohol and tobacco) and age at first intravenous (IV) drug use.

All participants were asked whether they smoked an illicit drug prior to initiating intravenous drug use. The majority of the respondents, $86 \%(n=791)$ reported that they had. There was no significant difference between the proportion of male (0.15) and female clients $(0.10)$ who went straight into intravenous drug use without smoking first. However, Table 1 illustrates that female respondents had a significantly shorter smoking career, prior to initiating intravenous drug use, than their male counterparts. Moreover, the time interval between first IV drug use and presenting at the health promotion unit was significantly shorter for the female clients.

Table 2 illustrates that there was no gender difference in clients reported use of primary drug over the four weeks prior to contact with the health promotion unit. The majority of both male $(92.2 \%)$ and female (90.7\%) clients reported using heroin as their drug of choice. Most of these clients also reported IV drug use. There was no statistically significant gender difference in reported frequency of use of primary drug, the majority of attenders reported daily IV drug use. Despite the fact that female clients had significantly shorter injecting careers, the odds ratio of daily IV drug use is 1.55 for women compared with 0.65 for men.

\section{Injecting practices and risk behaviour}

Table 2 also demonstrates that there were some notable gender difference in injecting practices. The odds ratios illustrate that female clients were significantly more likely than their male counterparts to report having problems finding an injecting site. The female respondents were also significantly less likely to report that they injected themselves. The odds ratio for injecting self is 0.35 for women, compared with 2.87 for men. In other words, they were more likely to need someone else to help with injecting.

With regard to injecting risk behaviour, analysis revealed that there was no significant gender difference in clients reporting the practices of sharing (either borrowed or lent) injecting equipment at some point in their IV drug using career. In terms of recent sharing behaviour, $15 \%$ of both the male 
and female clients report lending others their injecting equipment. Although not statistically significant, the female clients were proportionately more likely than their male counterparts to report borrowing used injecting equipment. The female clients were also significantly more likely to report the recent sharing of injecting paraphernalia, ie. spoons and filters.

\begin{tabular}{|c|c|c|c|c|}
\hline Gender & Male & Female & Missing & \\
\hline Variable & OR $(95 \% \mathrm{CI})$ & OR $(95 \% \mathrm{CI})$ & observations & $p$ value \\
\hline Using heroin* & $1.21(0.7-2.1)$ & $0.8(0.5-1.1)$ & 6 & $<0.472$ \\
\hline Injecting* & $0.92(0.5-1.6)$ & $1.10(0.6-1.9)$ & 8 & $<0.781$ \\
\hline Injecting daily* & $0.65(0.4-1.0)$ & $1.55(0.9-2.4)$ & 51 & $<0.053$ \\
\hline Poly-drug use* & $1.09(0.8-1.5)$ & $0.92(0.7-1.3)$ & 14 & $<0.605$ \\
\hline Living with injecting drug user & $0.59(0.4-0.8)$ & $1.69(1.2-2.3)$ & 11 & $<0.001$ \\
\hline Been to prison & $5.87(4.1-8.4)$ & $0.17(0.1-0.2)$ & 9 & $<0.001$ \\
\hline Shared needles/syringes & $0.75(0.6-1.0)$ & $1.34(0.9-1.8)$ & 19 & $<0.064$ \\
\hline Lent needles/syringes* & $0.99(0.7-1.5)$ & $1.01(0.7-1.5)$ & 19 & $<0.968$ \\
\hline Borrowed needles/syringes* & $0.72(0.5-1.0)$ & $1.38(0.9-1.9)$ & 23 & $<0.061$ \\
\hline Shared IV paraphernalia* & $0.56(0.4-0.8)$ & $1.79(1.3-2.5)$ & 25 & $<0.001$ \\
\hline Inject self & $2.87(2.0-4.0)$ & $0.35(0.2-0.5)$ & 31 & $<0.001$ \\
\hline Problem finding IV site & $0.24(0.2-0.3)$ & $4.15(2.9-5.9)$ & 22 & $<0.001$ \\
\hline Multiple sexual partners ${ }^{1}$ & $1.35(0.9-1.9)$ & $0.74(0.5-1.1)$ & 17 & $<0.109$ \\
\hline Regular sexual partner & $0.96(0.7-1.3)$ & $1.04(0.8-1.4)$ & 20 & $<0.813$ \\
\hline Injecting sexual partner & $0.11(0.1-0.2)$ & $9.04(5.9-13.9)$ & 33 & $<0.001$ \\
\hline $\begin{array}{l}\text { Shared needles/ } \\
\text { syringes with sexual partner }\end{array}$ & $0.26(0.2-0.4)$ & $3.83(2.7-5.5)$ & 24 & $<0.001$ \\
\hline Use condoms ${ }^{1}$ & $1.32(0.9-1.8)$ & $0.76(0.6-1.1)$ & 17 & $<0.077$ \\
\hline
\end{tabular}

*Four weeks prior to first contact

${ }^{l}$ Behaviour in the three months prior to contact with the health promotion unit

\section{Sexual risk behaviour}

Of the male clients, $26 \%$ reported having multiple sexual partners in the three months prior to contact with the health promotion unit, compared with $20.7 \%$ of the female clients. Table 2 shows that there was no significant gender difference in clients reporting having a regular sexual partner. However, of those who reported having a regular sexual partner, female clients were significantly more likely than the male clients to have a sexual partner who is an IV drug user. Among females the odds of having a sexual partner who is an injecting drug user is 3.25 , while among the male clients, the odds of having an injecting sexual partner is 0.36 .

Women were also significantly more likely to report sharing injecting equipment (borrowing and lending) with their partner. Furthermore, the female clients were, as illustrated in Table 2, significantly more likely to report living with an injecting drug user.

There were no significant gender difference in reported condom use. While $67 \%$ of the male client reported using condoms, $60.5 \%$ of the female clients also did so.

\section{Health and well-being}

Table 3 illustrates that there was no significant gender difference in reported contact with drug treatment services. Only $18.6 \%$ of the male clients and $19.5 \%$ of the female clients reported currently being in contact with other drug services in addition to the Merchant's Quay Project. 
However, female clients were significantly more likely to report having been to a GP in the three months prior to contact with Merchant's Quay Health Promotion Unit (OR $=2.84,95 \%$ CI, 2.13.9). This may be related to the fact that the female respondents were also significantly more likely to report having a medical card (70.6\%). This compared with $47 \%$ of the male clients.

Despite the gender difference in medical contact, the male respondents were significantly more likely to report having had a vaccination against hepatitis B (OR $=2.15,95 \% \mathrm{CI}, 1.4-3.4)$. The vaccination was reportedly taken by $22 \%$ of the male clients, compared with only $11.4 \%$ of the female clients. There was no gender difference in reportedly having had an HIV test.

As regards health complaints, Table 3 shows that the female clients were significantly more likely to report having abscesses and suffering from weight loss in the three months prior to contact with Merchant's Quay Health Promotion Unit. The female clients were also significantly more likely to report suffering from a range of mental health problems, e.g. depression, feeling unable to cope, feeling isolated and having suicidal tendencies.

\section{Discussion}

The misuse of drug by women is not a new or even surprising phenomenon. However, with the possible exception of the use of prescribed psychotropic drugs and over the counter analgesics, ${ }^{11}$ male drug users have tended to outnumber female drug users. Although this remains the case today the gap is steadily narrowing.

Many contemporary epidemiological studies demonstrate an increasing proportion of young women misusing a wide range of drugs. ${ }^{12,13}$ Moreover, in many country the numbers of female drug users is increasing at a faster rate than it is for males. ${ }^{14}$ In the context of the growth in absolute numbers, female drug users are still considered a minority of the total drug using population. However, it should be noted that there is an overall decrease in gender differences of illicit drug use among teenagers and young adults. ${ }^{15}$

It is difficult to predict a very accurate picture of the prevalence of female drug use because there is no way of determining the total number of women dependent on illegal drugs. In Britain, the Home Office figures over the last decade show a consistent figure of under $30 \%$ for notified female addicts. ${ }^{16}$ In Ireland, data collected by the Health Research Board for the Greater Dublin area illustrates that $22 \%$ of the total treatment contacts in 1995 were female, ${ }^{17}$ this increased slightly to $28 \%$ in $1996^{18}$.

The problem is that most of these figures are based on drug users who actually present for treatment, and it is generally recognised that only a small proportion of drug users, ${ }^{19}$ and in particular female drug users, ${ }^{20}$ are in contact with drug treatment services. This has been found to be the case in many international studies. ${ }^{20-22}$ Moreover, a number of barriers have been identified to women entering treatment. These include women's lack of economic resources, ${ }^{23}$ childcare concerns, ${ }^{24}$ and the perceived insensitivity of treatment setting to women's problems. ${ }^{25}$

\begin{tabular}{|c|c|c|c|c|}
\hline Gender & Male & Female & & \\
\hline Variable & OR $(95 \% \mathrm{CI})$ & $(\mathrm{OR}(95 \% \mathrm{CI})$ & $\begin{array}{c}\text { missing } \\
\text { observations }\end{array}$ & $p$ value \\
\hline In treatment & $0.94(0.6-1.4)$ & $1.06(0.7-1.6)$ & 2 & $<0.759$ \\
\hline Medical card & $0.37(0.3-0.5)$ & $2.69(1.9-3.7)$ & 20 & $<0.001$ \\
\hline Contact with $\mathrm{GP}^{1}$ & $035(0.3-0.5)$ & $2.84(2.1-3.9)$ & 19 & $<0.001$ \\
\hline HIV test ${ }^{1}$ & $0.99(0.7-1.3)$ & $1.01(0.7-1.4)$ & 34 & $<0.947$ \\
\hline Vaccination Hep $\mathrm{B}^{1}$ & $2.15(1.4-3.4)$ & $0.46(0.3-0.7)$ & 33 & $<0.001$ \\
\hline Abscesses $^{1}$ & $0.56(0.4-0.8)$ & $1.78(1.2-2.6)$ & 58 & $<0.012$ \\
\hline Weight loss ${ }^{1}$ & $0.72(0.5-1.0)$ & $1.38(0.9-1.9)$ & 56 & $<0.055$ \\
\hline Insomnia $^{1}$ & $1.02(0.7-1.4)$ & $0.98(0.7-1.4)$ & 52 & $<0.917$ \\
\hline
\end{tabular}




\begin{tabular}{lllll} 
Thrombosis $^{1}$ & $0.73(0.5-1.1)$ & $1.37(0.9-1.9)$ & 73 & $<0.097$ \\
Depression $^{1}$ & $0.42(0.3-0.6)$ & $2.36(1.6-3.4)$ & 52 & $<0.001$ \\
Anxiety $^{1}$ & $0.76(0.5-1.0)$ & $1.32(0.9-1.8)$ & 62 & $<0.078$ \\
Unable to cope $^{1}$ & $0.57(0.4-0.8)$ & $1.75(1.3-2.4)$ & 58 & $<0.001$ \\
Isolated $^{1}$ & $0.66(0.5-0.9)$ & $1.52(1.1-2.1)$ & 61 & $<0.008$ \\
Suicidal $^{1}$ & $0.49(0.4-0.7)$ & $2.01(1.4-2.8)$ & 64 & $<0.001$ \\
${ }^{1}$ This refers to the three months prior to contact & & & \\
\hline
\end{tabular}

One Irish study has, however, attempted to estimate the prevalence of opiate use in Dublin. Comiskey ${ }^{26}$ employed the capture-recapture methodology using data from three different sources: the central patient methadone treatment list, the hospital inpatients enquiry database and police arrests. The estimated total number of opiate users was put at 13,460 and the ratio of male to female opiate users was estimated to be 3:1. The gender ratio of first time attenders at the Merchant's Quay Health Promotion Unit is the same.

This indicates that the health promotion unit does not deter new female presenters. This is further supported by the fact that the time interval between first use of drugs and first presentation at the service was significantly shorter for women. If women were deterred from attending the unit, then the delay between onset of drug use and first presentation should be greater.

This early presentation by female clients may in part be due to the fact that the rate of physical and mental deterioration is, as other research suggests, more rapid among injecting women, so they quickly reach the state of requiring treatment. ${ }^{22,27}$ There is some evidence to suggest that this may be the case among the women attending the Merchant's Quay Health Promotion Unit.

Firstly, although there was no significant gender difference in drug use, the female clients in this study, despite their significantly shorter injecting careers, were proportionately more likely to inject their primary drug daily. Moreover, the women were significantly more likely to report suffering from injecting related problems such as difficulty finding IV sites, having abscesses and thromboses.

Secondly, the women were more likely than their male counterparts to report suffering from mental health problems, such as depression, anxiety, feeling unable to cope and feeling isolated. This is supported by international research which has found that women drug users complain of a range of medical and psychological problems more often, and to a greater extent than do their male counterparts. ${ }^{28}$ Indeed it is often medical complaints that precipitate women's entrance into drug treatment. ${ }^{29}$

However, one cannot ignore the possibility that, as other research indicates, women are simply more likely to admit to having health problems and are more likely to attend medical services than men. ${ }^{30}$ This is highlighted by the fact that the female drug users in this study were significantly more likely than their male counterparts to report having had recent contact with a GP.

This study also shows important gender differences in terms of the extent of personal involvement with other drug users. The female attenders were significantly more likely to be involved in a sexual relationship with an injecting drug user. These findings are consistent with those of studies in both the $\mathrm{UK}^{16}$ and the US. ${ }^{22}$ Moreover, it was also found that women were significantly more likely to report living with an injecting drug user. Research in the UK has found that living with an injecting drug user is related to the sharing of injecting equipment and paraphernalia, primarily because it creates a social environment that leads to sharing. ${ }^{31}$

The greater personal involvement of women with other drug users highlighted in this study could have considerable impact on prognosis and clinical intervention, by simultaneously depriving them of protective factors and exposing them to high risk factors. ${ }^{16}$ This in turn has implications for service providers. However, it has been shown that the availability of social support is a predicator of abstinence and good treatment outcomes. ${ }^{32}$

The fact that women are presenting at an earlier stage in their drug taking cycle poses a particular challenge to drug treatment services to design programmes that engage rather than alienate women. Adopting a client-centred approach is essential in this regard and should be complemented by the provision of a woman-only service. When we consider the dual factors of female drug users presenting younger and at an earlier stage, it creates a hopeful picture. 
Although there is no evidence to date to substantiate claims that interventions with younger drug users are necessarily more successful or effective, there are certain implications which might have positive outcomes for treatment initiatives. These outcomes relate more specifically to influencing drug usage patterns, thereby reducing risk behaviour; persuading young drug users to engage in drug treatment services and progressing young drug users incrementally towards a consideration of a drug free lifestyle.

To conclude, this research has illustrated that the question of number is really a non-issue. What is important is the fact that young women drug users exist, and that they are more likely than their male counterparts to engage in risk behaviour which has a detrimental effect on their mental and physical health.

However, the findings of this study have illustrated that female drug users are more willing to acknowledge these difficulties and seek help. The challenge is to harness their needs or requests for assistance into non-judgemental client-centred services which not only engage them in their crisis but also sustains their participation across a range of treatment options. This will provide the opportunity to build sequentially on their progress and development which may involve a progression from chaotic drug use to an independent, sustainable drug-free lifestyle.

\section{Acknowledgements}

The authors are indebted to the clients of the Merchant's Quay Project without whom this research would have been impossible. We are grateful to the staff of the health promotion unit for enthusiastically cooperating with the research. We are also very grateful for the technical assistance provided by Marie Lawless. The Merchant's Quay project is a voluntary organisation funded in part by the Department of Justice, EHB, FAS, Inner City Trust, the Franciscan community and various private grants and donators.

\section{Reference}

1. Single E. Defining harm reduction. Drug Alcohol Rev 1995; 14: 287-90.

2. Newcombe R. The reduction of drug related harm: a conceptual framework for theory, practice and research. In: O'Hare P, Newcombe R, Matthews A, Buning U, Drucker U (eds). The reduction in drug-related harm. London: Routledge, 1992.

3. O'Connor J, Stafford-Johnson S, Kelly M. A review of the characteristics and treatment progress of 45 pregnant opiate addicts attending the Irish National Drug Advisory and Treatment Centre over a two year period. Irish J Med Sci 1988; 157 (5): 146-9

4. Keenan E, Dorman A, O'Connor J. Six year follow-up of 45 pregnant opiate addicts. Irish J Med Sci 1993; 162 (7): 252-5

5. Harrell A. Validation of self-report: the research record. In: Rouse B, Kozel N, Richards L (eds). Self-report methods of estimating drug use: meeting current challenges to validity. NIDA, Rockville 1985; 12-21

6. Bradburn N, Rips L, Shevell S. Answering autobiographical questions: the impact of memory and inference on survey. Science 1987; 236: 157-61

7. Siegel K, Bauman L. Methodological issues in AIDS-related research. In: Feldman D, Johnson T (eds). The social dimensions of AIDS: methods and theory. New York: Praeger 1986; 15-39.

8. McElrath K, Chitwood D, Griffin D, Comerford M. The consistency of self-reported HIV risk behaviour among injecting drug users. Am J Public Health 1994; 84 (12): 1965-70.

9. Kleun J, Schwebke J, Holmes K. The validity of injecting drug users self-report about sexually transmitted disease: a comparison of survey and serological data. Addiction 1994; 88: 673-80. 
10. Anthony $\mathrm{J}$ et al. Self-report interview data for a study of HIV-1 infection among intravenous drug users: description of methods and preliminary evidence on validity. J Drug Issues 1991; 21: 739-57.

11. Ettorre F. Women and substance use. London: Macmillan, 1992.

12. Ghodse A et al. The effect of maternal narcotics addiction on the new born infant. Psychol Med 1977; 667-75

13. Parker H, Measham F. Pick ' $n$ ' mix: changing patterns of illicit drug use amongst 1990s adolescents. Drugs: Education, Prevention and Policy 1994; 1 (1) 5-13.

14. Sanchez J, Johnson B. Women and the drugs-crime connection: crime rates among drug abusing women at Riker Island. J Psychoactive Drugs 1987; 19: 205-16.

15. Hser Y, Anglin d, McGlothlin W. Sex differences in addict careers: 1. Initiation of use. Am J Drug Alcohol Abuse 1987; 13 (1,2): 33-57.

16. Gossop M, Griffiths P, Strang J. Sex differences in patterns of drug taking behaviour. Br. J Psychiat 1994; 164: 101-4.

17. O'Higgins K, Duff P. Treated drug misuse in Ireland: first national report 1995. Dublin: Health Research Board, 1997.

18. Moran R, O'Brien M, and Duff P. Treated drug misuse in Ireland: national report 1996. Dublin: Health Research Board, 1997.

19. Hartnoll R, Mitcheson M, Lewis R, Bryer S. Estimates of the prevalence of opioid dependence. Lancet 1985; 203-5.

20. Berridge V. Drugs research and policy in Britain. Avebury, Aldershot 1990.

21. Paone U, Des Jarlais D, Gangloff R, Milliken J, Friedman S. Syringe exchanges: HIV prevention, key findings and future direction, Int J Addict 1995; 30 (420): 1647-83.

22. Anglin M, Hser Y, Booth M. Sex differences in addict careers. 4. Treatment. Am J Drug Alcohol Abuse 1987; 13: 253-80.

23. Hodgins D, El-Guebaly N, Addington J. Treatment of substance abusers: single or mixed gender programs? Addiction 1997; 92 (7): 805-12.

24. Cuskey W. Female addiction: a review of the literature. Focus on women: J Addict Health 1982; 13 (1): 3-33.

25. Reed B. Developing women-sensitive drug dependence treatment services: why so difficult? J Psychoactive Drugs 1987; 19 (2): 151-64.

26. Comiskey C. Estimating the prevalence of opiate use in Dublin, Ireland during 1996. Tallaght: Institution of Technology, 1998.

27. Moise R, Reed B, and Ryan V. Issues in the treatment of heroin-addicted women: a comparison of men and women entering two types of drug abuse programs. Int J Addict 1982;17 (1): 109-39.

28. Mondararo J. Chemically dependent women: assessment and treatment. Massachucsette: Lexington Books, Lexington, 1989.

29. Rosenbaum M, Murphy S. Not the picture of health: women on methadone. J Psychoative Drugs 1987; 19 (2): 217-26.

30. Cooperstock R. Sex differences in the use of mood-altering drugs: an explanatory model. J Health Social Behav 1971; 12: 238-44

31. Donoghoe M, Dolan K, Stimson G. Lifestyle factors and social circumstances of syringe sharing in injection drug users. Br J Add 1992; 87: 993-1003.

32. Gossop $\mathrm{M}$ et al. Factors predicting outcome among opiate addicts after treatment. Br J Clin Psy 1990; 29: 209-16. 